Fuel

February 2015, Volume 141 Pages 173-184

http://dx.doi.org/10.1016/i.fuel.2014.10.041

http://archimer.ifremer.fr/doc/00245/35580/

(C) 2014 Elsevier Ltd. All rights reserved.

\title{
Exploring methane-hydrate formation and dissociation in geologic materials through laboratory experiments: Kinetic behavior and morphology
}

\author{
Ruffine Livio ${ }^{1, *}$ \\ ${ }^{1}$ IFREMER, Dept REM, Unite Geosci Marines, F-29280 Plouzane, France.
}

Corresponding author Livio Ruffine, email address : livio.ruffine@ifremer.fr

\begin{abstract}
:
To gain in-depth understanding of natural gas hydrate behavior it is necessary to identify key parameters that affect their formation, distribution and destabilization within sediments. Hydrate formation kinetics in porous media is amongst the aspects which deserve important considerations as it may provide useful information on the formation history and the formation mechanisms of natural gas hydrate accumulations. Yet, it is at its early stage. In this paper, experiments on methane hydrate formation and dissociation in porous media are reported and discussed. The first part of this work is devoted to the investigation of the kinetics of methane hydrate formation within silica sand using a custom-design apparatus. The latter is suitable for investigating small hydrate-bearing cores. The influence of the methane injection flow-rate is examined, and then a straightforward method is proposed to quantify the amount of hydrate-bound gas. In the second part, three mixtures of clays and sand are used as geologic matrix to study the influence of clay content on the hydrate morphology for a predetermined amount of injected water. Visual observations showed that the morphology shifts from disseminated through massive to moussy hydrates with increasing proportion of clays.
\end{abstract}

\section{Highlights}

A novel apparatus for studying hydrate formation in geologic matrices is presented. Kinetics of methane-hydrate formation in sand was investigated. Influence of methane injection rate was studied. Repeated experiments at constant methane injection flow rate showed different formation patterns. Morphology of hydrates in sand-clay mixtures changes with the proportion of clay.

Keywords : Geologic matrices, Hydrate morphology, Kinetics, Methane hydrates, Novel apparatus 


\section{Introduction}

Natural gas hydrates are crystalline compounds resulting from the enclathration of small molecules, primarily methane, into a water lattice [1-4]. They are found in marine sediments of continental margins and in the permafrost regions $[2,5,6]$, and represent one of the major organic carbon reserves on earth $[5,7]$.

Currently, natural gas-hydrate accumulations are regarded as a double-edged sword: while they are considered as both a potential energy resource [8-13] and huge carbon dioxidestorage reservoirs [14-20], they are also defined as a geohazard [21-25] and often presented as a potential climate-change contributor [26-32]. This makes its study a timely topic as reflected by the increasing number of related articles available from scientific reviews. In fact, the scientifically established literature offers a very broad spectrum of natural gas-hydrate study ranging from field investigations through laboratory experiments to modeling, and from the microscale to the macroscale level (see Sloan and Koh [4], Waite et al. [33] and references herein).

The kinetics of natural gas-hydrate formation within geologic materials is perhaps one of the less studied aspects related to their occurrence in nature. By definition, it deals with the nucleation mechanism and the incipient hydrate-formation time, the distribution points of these nuclei and the rate at which hydrates grow within the sediment. Thus, kinetics may provide useful information on the formation history and the formation mechanisms of natural gas-hydrate accumulations. Recently, Sultan et al. [34] have experienced the release of a huge amount of free gas from a gas hydrate-bearing sedimentary interval during the drilling of a giant pockmark in the Gulf of Guinea. They argued that such a coexistence of free gas and gas hydrates is indicative of a deposit where hydrates grow at a rate high enough to trap free gas in between the crystals. In a previous work, Torres et al. [35] proposed the same interpretation to constrain the coexistence of free gas, gas hydrates and chloride-enriched pore fluids at the southern summit of Hydrate Ridge. These two examples illustrate well the influence of the kinetics of formation on the hydrate deposit characteristics. However, when focusing only on the kinetics of hydrate formation in porous media where methane is the guest molecule, one can quickly realize that the available literature is very limited. In a state-of-art review on gas 
hydrate research, Sun et al. [36] highlighted the difficulties of investigating hydrate formation kinetics in porous media through laboratory experiments. Those difficulties are mainly related to the control of heat and mass transfers within the porous medium as mentioned by Sun and Mohanty [37]. Accordingly, hydrate-formation kinetics has to be investigated with great prudence due to the implication of many specific factors like the gas transport process, the nature of the geologic matrix, the gas flux intensity when free gas is involved, the pore fluid chemistry, the degree of supersaturation and subcooling which are likely to impinge it [36, 38-46]. This makes the evaluation of the relevance of each specific factor very difficult. Hence, well-designed experiments where only one or very few parameters vary whereas the others are kept constant are often required to achieve this goal.

The kinetics of formation may also influence hydrate morphology. The latter is a foundational topic when studying hydrate occurrence and distribution in nature [47]. Field observations highlight that hydrates occur at two different morphologies depending of the nature of the sediments [33]: disseminated in coarse-grained sediments and massive hydrates as lenses and nodules in fine-grained sediments. While disseminated hydrates result from pore-filling, loadbearing or cementing habit, only the latter two lead to massive hydrates. The last recent years, investigators have made a lot of efforts to develop experimental systems to mimic natural gashydrate formation in order to either observe or infer the resulting morphology. Laboratory experiments of hydrate formation in coarse-grained sediments from dissolved gas are very time-consuming and often lead to low hydrate saturation levels. Such a formation method leads to pore-filling habit because of the excess water configuration usually applied [33]. However, Spangenberg et al. [48] achieved a saturation level as high as 95\% after 55 days of continuous experiment of hydrate formation from dissolved methane in glass bead samples. Priest et al. [49] claimed that with hydrate saturation above $40 \%$ the habit changes from porefilling to frame-building (i.e. load-bearing or cementing hydrates). From a macroscopic point of view the hydrates would appear as disseminated due to the coarse-grained matrix. When the geologic matrix is partially or fully saturated with water prior to free-methane injection, frame-building habit prevails, leading to load-bearing or cementing hydrates [33, 49]. Tohidi et al. [45] and Madden et al. [42] have observed the formation of massive hydrates 
preferentially in areas favorable for gas accumulations. Su et al. [50] drew similar conclusions from experiments performed in a three-dimensional simulation device to investigate hydrate formation and distribution in porous medium. Both experimental results are in agreement with observations reported from natural hydrate settings where massive gas hydrates are found in faulted and fractured sedimentary structures conducive to free-gas accumulation $[35,51,52]$. This paper reports experimental results from the kinetics of methane hydrate formation in silica sand and the resulting hydrate morphology from their growth in mixtures of sand and clays. Hydrate dissociation pattern is also discussed, together with the quantification of the hydrate-bound methane.

\section{Experimental study}

\section{a. Apparatus}

\section{Conception strategy}

In nature, the hydrate forming gas is either generated in situ or migrates upwards from deeper sources. Therefore, the required apparatus has to be able to simulate natural gas transport processes. It should also allow the study of all aforementioned specific factors influencing the hydrate formation kinetics in a reliable way, through experiments where sediment composition is well controlled and the amount of gas bound within the hydrates fairly estimated. This approach would for instance enable us to identify the critical clay composition for which hydrate morphology moves from disseminate to massive specimens for a matrix made up with sand and clays. Furthermore, it should be possible to retrieve the newly created hydrate-bearing core in a quick and easy way from the high-pressure vessel in order to appreciate both the morphology and the distribution of hydrates from naked eyes without too much disturbance due to depressurization; as it is usually done for cores recovered from natural hydrate settings. This apparatus should also allow the simulation of different hydrate production methods in order to investigate on the system's response to physical and chemical perturbations. Accordingly, it should be versatile enough to be implemented with various (1) analytical instruments such as chromatograph-connected high-pressure sampler to monitor the chemical evolution of both pore fluid and produced gas, (2) sensors such as thermal probe and 
well-acting tubing to investigate the effects of thermal perturbation or chemical injection on hydrate accumulations.

\section{Description}

Following the criteria mentioned above, the apparatus has been designed to create hydratebearing cores of $170 \mathrm{~mm}$ length and $60 \mathrm{~mm}$ diameter from a wide variety of sediments (from pure sand to clay-rich sediments) at most of temperature and pressure conditions encountered in nature. Fig. 1 shows a schematic diagram of the set-up. The heart of the latter is a $316-\mathrm{L}$ stainless-steel high-pressure vessel of $500 \mathrm{~mL}$ from TOP-Industrie (F-77013 Vaux Le Penil, France). It can be operated at pressures up to $22 \mathrm{MPa}$ and for temperatures ranging from 253 to $373 \mathrm{~K}$. It has been mounted vertically to better simulate fluid migration into a sedimentary column. Two flanges, one located at the top and the second one at bottom, ensure for the sealing of the system by mean of a PTFE gasket. Both flanges have five high-pressure fluid ports: four equally distributed over a circle located at the periphery of the vessel chamber for the connection of $1 / 8$ " tubing, and one for the connection of $9 / 16$ " tubing at the center (Fig. 1). The vessel is housed in a thermal jacket and connected to a cooling/heating circulator bath Ministat 230 from Huber capable of thermal regulation between 230 and $473 \mathrm{~K}$, with a claimed temperature stability of $0.02 \mathrm{~K}$. Temperature and pressure are measured with a 150 mm length DMESA thermocouple $\mathrm{K}$ located at the top of the vessel and a type P-31 pressure transducer from Wika located at the bottom, respectively. Both are connected to a $6100 \mathrm{E}$ paperless graphic recorder from Eurotherm for continuous data logging. The uncertainties were less than $\pm 0.2 \mathrm{~K}$ and $0.02 \mathrm{MPa}$ for the measurements of temperature and pressure, respectively. Both methane and water can be supplied through 1/16" tubing at pressures up to $20 \mathrm{MPa}$, either from the top or the bottom of the vessel. The former is supplied by a highpressure mass flow regulator Bronkhorst F230M working in a flow rate ranging from 10 to $500 \mathrm{mLn} / \mathrm{min}$ and with an accuracy better than $0.1 \%$ of its full scale (FS), while the latter is supplied by a high-pressure compact Coriolis mass flow controller Bronkhorst M12 coupled with an Eldex Opto metering pump. The Coriolis mass flow controller M12 works in a flow rate range from 0.05 to $2.5 \mathrm{~g}$ of water/min and with an accuracy better than $0.2 \%$ of the FS. 
The pump can be operated at pressures up to $41.3 \mathrm{MPa}$ and for flow rates ranging from 0.002 to $2.5 \mathrm{~mL} / \mathrm{min}$.

Water is injected at constant pressure using a pressure regulator P532C coupled with a Vary-P F033 valve, both from Bronkhorst. The working pressures of the P532C range from 8 to 40 $\mathrm{MPa}$, with an accuracy better than $0.5 \%$ of the FS. The total amount of water used for each experiment is determined by weighting before and after injection. A gas-water separator system with two outlets, one for gas and one for liquid, is located downstream and is connected to the top of the vessel (Fig. 1). It is composed of a high-pressure stainless-steel membrane-filter 130HPMX from GENIE for gas and water separation, connected to a pressure regulator P532C coupled with a Vary-P F033 valve at the liquid outlet. A second pressure regulator P532C coupled with a mass flow controller F210-CV from Bronkhorst is connected at the gas outlet. The working flow rates of the F210-CV range from 0.05 to 3.5 $\mathrm{mLn} / \mathrm{min}$, with an accuracy better than $1 \%$ of the FS. The purpose of the gas-water separator system is double: (1) When the gas outlet is closed, it acts as a back pressure regulator during hydrate formation. In addition, for hydrate destabilization experiments, it allows to maintain a constant pressure during either thermally-driven dissociation or dissolution by constant waterflow injection. (2) When the gas outlet is open, the second pressure regulator P532C enslaves the F210-CV to allow the quantification of the hydrate-bound gas. Data acquisition and processing of all regulators and controllers are performed using the Bronkhorst software Flow DDE2, Flow View and Flow Plot installed on a personal computer. All regulators, recorder and water tank are mounted on a half meter square PTFE sheet of $20 \mathrm{~mm}$ thickness, and the whole apparatus stands on $\sim 1 \mathrm{~m}^{2}$ space of a laboratory bench.

\section{Methodology}

\section{Chemical materials}

Purified water $\left(18 \mathrm{M} \Omega . \mathrm{cm}\right.$ at $\left.25^{\circ} \mathrm{C}\right)$ from a Milli-Q water system was used in this study after degassing by boiling. Methane was purchased from L'Air Liquide with a specified minimum purity of $99.995 \%$ and used as received without further purification. The well-calibrated sand 
of Fontainebleau (Laboratoires Humeau, La Chapelle-sur-Erdre) was used for all experiments. It is silica sand characterized by grain size ranging in between 180 and $500 \mu \mathrm{m}$. The kaolinitedominant matrix (called clay-matrix thereafter) was a commercial sample kindly offered by SOKA-Kaolin (Saint-Brieuc, France). Its weight composition is of $75 \%$ kaolinite, $18 \%$ illite and $7 \%$ quartz, and consists of $99 \%$ of the particles sizing less than $20 \mu \mathrm{m} ; 85 \%$ less than 10 $\mu \mathrm{m}$ and $38 \%$ less than $2 \mu \mathrm{m}$.

\section{Hydrate formation procedure}

Two procedures derived from the excess gas method were tested for hydrate formation where water was injected first, followed by methane. They differ from each other by the methane injection procedure.

\section{Sediment core preparation}

The position of the fluid injection ports was ideally located at the center of each flange of the cylindrical vessel chamber to allow a centered distribution. However, with the aim of achieving uniformity in the fluid distribution, two porous stones of $6 \mathrm{~mm}$ thickness were placed at either end of the core (Fig. 1). Sediment core was directly prepared within the vessel. The first porous stone was placed at the bottom of the vessel, and then the geologic matrix was injected as powder. The vessel was filled until only space for the second porous stone at the top was left, and then it was sealed. The core was compacted by applying a vacuum pressure of $3 \times 10^{-4} \mathrm{MPa}$ from the gas inlet. The vessel was unsealed again to fill with sediment the vacuum space generated by compaction. The whole sediment injection procedure was repeated until no further sediment powder can be added into the vessel. Reasonable compaction was not achieved for the two matrices containing the highest \%-mass of clay. Therefore the sediment was considered as unconsolidated. The high agglomerating capacity of clays made difficult the determination of porosity for the clay-containing cores. However, it was determined for the silica sand cores, with values of 0.48 and 0.47 for cores with grain size in between $180-500 \mu \mathrm{m}$ and 180-360 $\mu \mathrm{m}$, respectively. It can be noted that reducing the range of grain size does not change considerably the porosity here. 
In order to calculate precisely the amount of gas contains in the hydrates, the total amount of injected water needs to be accurately known. Therefore, for either procedure, $100 \mathrm{~g}$ of water at $293.15 \mathrm{~K}$ was injected into the high-pressure vessel directly from the $9 / 16$ " port located at the top. Meanwhile a slight vacuum was applies from the bottom of the vessel to facilitate both the water injection and its diffusion throughout the sedimentary column. The choice of $100 \mathrm{~g}$ of water was motivated by the fact that this corresponds to $40 \%$ water saturation when working with a sand matrix characterized by a grain size range from 180 to $500 \mu \mathrm{m}$. The system was then fully evacuated from the residual air and its temperature was kept at 293.15 $\mathrm{K}$ for $24 \mathrm{~h}$ to allow homogeneous distribution of the water. Several water-injection tests at the experimental conditions were carried out to determine the time required to obtain a visually homogeneous distribution of water within the sandy matrix. The results showed that $24 \mathrm{~h}$ was enough. Furthermore to make sure that there was no loss of water during the vacuum; a filter containing Drierite desiccants with indicator (gypsum) was placed at the inlet of the vacuum pump to testify that water has not been lost. The water injection has been optimized to avoid potential loss and if there was any, the experiment was stopped, the matrix was replaced and a new experiment was started.

\section{Methane injection}

Two procedures have been considered here. The first procedure consists on injecting methane at a constant flow rate of $57 \mathrm{mLn} / \mathrm{min}$ until the system pressure nearly balances the pressure of the gas bottle. The system was left at $293.15 \mathrm{~K}$ for another $24 \mathrm{~h}$, and then the temperature was set to around $274.15 \mathrm{~K}$ to allow the system to be located well inside the hydrate stability field. Hydrate formation was detected from an increase in temperature and a pressure drop down to the methane hydrate equilibrium pressure at the temperature of the experiment (Fig. 2). This procedure very often leads to the plugging of the gas inlet by hydrates, making difficult the reinjection of methane. However, in the example presented here a second methane injection cycle was possible after $\sim 50$ hours of experiment (Fig. 2) by heating up the vessel inlet. Such a heating step could dissociate not only the hydrates which plug the vessel inlet, but also those located within the vessel. Therefore, heating was abandoned and no second methane injection was performed for the other experiments. As regards the second 
procedure, after the water injection and the $24 \mathrm{~h}$ waiting at $293.15 \mathrm{~K}$, the system was set to around $274.15 \mathrm{~K}$ for $12 \mathrm{~h}$. Methane was injected afterward at a constant and predetermined flow rate until the system pressure nearly balances the gas bottle one. Here, the hydrate formation and growth were characterized by very pronounced temperature increase and pressure drop as can be seen in Fig. 3.

\section{Quantification of the hydrate-bound methane}

In this work, a straightforward method to quantify the amount of hydrate-bound gas has been developed, allowing a direct estimation of the hydrate saturation level. Pore space volume change was neglected in the calculation as the coarse-grained sediment core was packed and confined within the high-pressure vessel. Moreover, during the dissociation step gas was allowed to flow continuously through the mass flow controller. This enhances pressure dissipation and limits the volume change. Fig. 4 shows the evolution of the system pressure as a function of time upon depressurization. During the entire dissociation step, methane is released from the mass flow controller-coupled pressure regulator, at a constant flow rate of $3.5 \mathrm{mLn} / \mathrm{min}$.

The graph from Fig. 4 can be divided in three distinct regions: Region 1 corresponds to the release of the free methane occupying the hydrate-free pore space and tubing. Once the system pressure reaches the hydrate-equilibrium phase boundary, hydrates start to dissociate at a nearly constant pressure which corresponds to the hydrate equilibrium pressure (region 2 in Fig. 4). The pressure variation between the beginning and the end of the hydrate dissociation step is less than 4 bars for all experiments. Finally once the hydrates were entirely dissociated, the pressure starts decreasing again (region 3 in Fig. 4) due to the exsolution of methane from the hydrate water. Knowing the time elapsed during the hydrate dissociation step, the pressure of dissociation and the flow rate applied for the methane release, it becomes easy to calculate the amount of methane previously trapped into the hydrates. It is obtained by multiplying the time elapsed during the hydrate dissociation step by the flow rate of dissociation. The hydrate dissociation time was taken as the elapsed time defined by the two tangents delimiting the three regions (Fig. 4). The accuracy of the gas volume measurement is within $\pm 0.22 \mathrm{~L}$. It has been calculated by taking into account the 
slight decrease of pressure during hydrate dissociation for the correction of the flow rate and the accuracy regarding the determination of the tangent-delimited domain. It is worth noting that the gas quantification would be even more useful when studying $\mathrm{CO}_{2} / \mathrm{CH}_{4}$ hydrate exchange within sediment. In fact, combined with the compositional analysis of the hydratebound gases, it constitutes a valuable tool to estimate both the efficiency of the exchange and the $\mathrm{CO}_{2}$ storage capacity.

\section{Sediment core recovery}

The retrieval of the hydrate-bearing sediment core from the vessel was based on the procedure used on ship for the recovery of none-pressurized gravity core. To facilitate the retrieval, the inner wall of the vessel was draped with a $0.5 \mathrm{~mm}$ thickness of polypropylene sheet prior to each experiment. Thus, after each experiment of hydrate morphology study, the vessel was depressurized by dropping the pressure to the atmosphere from the top. This operation takes between 7 to 12 minutes and leads to a decrease in the system temperature. Caution was taken to avoid a temperature decrease below $273.15 \mathrm{~K}$, which would promote ice formation. The top flange was taken out by undoing the 6 bolts, followed by the porous stone. The core was then withdrawn by pulling outside the polypropylene sheet. Finally, the sheet was cut lengthwise and the core was collected for visual inspection. The whole core recovery operation takes less than 15 minutes.

\section{Results and discussion}

a. Experiments at constant methane injection flow-rate: similarity and singularity Several experiments at $40 \%$ water saturation have been carried out by applying the two methods of hydrate formation in order to identify what are common from one experiment to another and what are different. Fig. 5 and 6 represent the results obtained using method 1 and 2 , respectively, for sand grain size ranging in between 180-500 $\mu \mathrm{m}$. Method 1 systematically drives the system to the hydrate equilibrium pressure in less than 5 hours after lowering the temperature (Fig. 5). Thus the maximum of free water was converted into hydrates meanwhile obeying to the equilibrium thermodynamic laws. For all three experiments there was no 
significant difference between the inlet and outlet pressures suggesting no disruption of the hydraulic conductivity between both ends of the core, and therefore enabling the fluids to flow through. Thus, only evolution of the inlet pressure with time is presented. One can see that the drop to the hydrate equilibrium pressure is overall quite smoothed, with little difference from one experiment to another. Only experiment C (Exp_C) truly exhibits a different pattern with a pressure plateau of $\sim 2 \mathrm{~h}$ at 53 bars, followed by a pressure decrease. This plateau suggests that the hydrate nucleation and/ or growth have been stopped for $2 \mathrm{~h}$, and then have restarted to take the system to equilibrium pressure.

The evolution of pressure and temperature as a function of time for the ten first hours from method 2 are shown in Fig. 6a and 6b, respectively. It is a series of experiments carried out at a methane flow rate of $57 \mathrm{mLn} / \mathrm{min}$. The slope of the pressure curve for Exp_1 at the beginning of the experiment is smaller. This is due to the fact that the downstream P532C coupled with the F-210CV was left connected to the vessel during the hydrate formation step, i.e. the gas outlet of the gas-water separator system was on. This extra volume significantly increases the total volume of the system to pressurize, and thus reducing the speed of the pressure rise. All others experiments were carried out with the liquid outlet of the gas-water separator system on whereas the gas outlet was off; except when the hydrate-bound methane was quantified. Nevertheless, one can clearly see that for all experiments the hydrate formation is always accompanied by an important pressure drop correlated with an important temperature rise. The pressure drop can be as important as 30 bars while the temperature rise can be up to $3.8^{\circ} \mathrm{C}$ above the set value. However, both the incipient of hydrate formation and the pressure decrease pattern are different from one experiment to another. This is also the case for the temperature as observed in Fig. 6b. The intensity of the temperature rise is probably related to both the growth rate and the distance between the thermocouple and the hydrate-growth point. The closer the hydrate-growth point is to the thermocouple, the stronger is the temperature rise as this process lead to the release of a high amount of heat. Table 1 summarizes both the incipient hydrate-formation time (often called induction time) and pressure obtained for each experiment. They range in between 52 and $138 \mathrm{~h}$, and 48.99 and 75.55 bars, respectively. This series of experiments clearly indicates that the incipient hydrate 
formation strongly depends on factors other than the methane flow rate. The shapes observed for the pressure curve also depict different hydrate nucleation and growth patterns, highlighting the singular nature of each experiment when using method 2 [53].

\section{b. Influence of the methane injection flow-rate on the kinetics of hydrate}

\section{formation and quantification of the hydrate-bound methane}

From the series of experiments presented above, it is not clear whether the methane injection flow-rate has a major influence on the hydrate formation kinetics as the incipient hydrateformation time can more than double from one experiment to another at the same experimental conditions. In order to have a more precise idea on the impact of this parameter, we performed five experiments at different methane injection flow-rate. Meanwhile, the methane-storage capacity of the hydrates was also determined by measuring the amount of hydrate-bound methane. Fig. 7 presents the evolution of three parameters, the upstream (core bottom) and downstream (core top) pressure and the temperature, as a function of time for different methane injection flow-rates. Upstream and downstream pressures do not necessarily coincide with each other during the whole experiment. Fig. 8 shows a magnified view of the time segment corresponding to the hydrate formation step. As for all the experiments performed at $57 \mathrm{mLn} / \mathrm{min}$, the variety of shapes obtained for the time-pressure curves during the hydrate formation step is in agreement with the stochastic pattern of hydrate nucleation and growth within a matrix and its impact on the fluid flow [41, 53, 54]. For experiments performed at 85 and $171 \mathrm{mLn} / \mathrm{min}$, the hydrate growth pattern led to a complete plugging of both pressure transducers before reaching the methane bottle pressure (110 bars). Therefore, plugs of hydrates may form at either pressure transducer at any time. It is also worth noticing that at low methane injection flow-rate both pressure curves exhibit a smoother trend; suggesting a system less affected by flow turbulences during hydrate formation. A possible explanation may be the occurrence of a few number of hydrate nucleation and growth points in the uniformly distributed pore water, leading to less disturbance of the hydraulic conductivity. Another possible explanation is to consider water migration and redistribution which may occur at high gas injection flow-rates, leading to intricate trends. The hydrate distribution will become heterogeneous due to the formation of more scattered nucleation and 
growth points, and thus changing more significantly the hydraulic conductivity between both core ends.

Table 2 summarizes key parameters related to the experiments. Although the values obtained for the incipient hydrate-formation time are not absolute as demonstrated in the previous section, they give a certain idea concerning the time needed to form hydrates within the sediment core. Thus, one can clearly see that the incipient hydrate-formation time considerably decreases until a limit value when increasing the methane injection flow-rate as displayed in Fig. 9. Here, the lowest value of incipient hydrate-formation time is observed for a flow rate of $114 \mathrm{mLn} / \mathrm{min}$ although the latter does not correspond to the highest flow rate used in the study. However, we have to keep in mind the scattering obtained for incipient hydrate-formation times from repeated experiments at a flow rate of $57 \mathrm{mLn} / \mathrm{min}$. Therefore we believe it is preferable to consider that the incipient hydrate-formation time tends toward a value of around $30 \mathrm{~min}$ when increasing the methane flow rate. Thus, these experiments together with the previous ones have to be interpreted as first results which open new directions in investigating hydrate formation kinetics. It would certainly deserve deeper attention by carrying out a more comprehensive campaign of measurements.

The measured volumes of hydrate-bound methane range in between 17.31 and $19.78 \mathrm{Ln}$. Knowing that $100 \mathrm{~g}$ (i.e. $100 \mathrm{~mL}$ ) of water was injected, and 1 volume of hydrates contains between 150 and 184 volumes of methane at STP $[4,5,7,12]$, we can claim that the whole injected water was converted into hydrates. The experiment performed at the highest methane flow rate led to a volume of hydrate-bound gas greater than that expected. This suggests a high growth rate with trapping of gas molecules within the hydrate fabric [34,55]. The results do not show a particular relationship between the methane injection flow-rate and the volume of enclathrated gas. It should be noted that using method 1 led to a volume of hydrate-bound methane of $\sim 11 \mathrm{Ln}$ for two repeated experiments. Moreover, as mentioned earlier, the reinjection of methane was not very successful due to the occurrence of hydrate plugs at the vessel inlet. This impedes the interactions between methane and the remaining free water, and thus further inhibits the hydrate formation. Accordingly, method 2 is more efficient than method 1 if one wants to achieve a total conversion of water into hydrates. 


\section{c. Morphology of hydrates within $\{$ sand + clays $\}$ mixtures}

The morphology of natural gas hydrates deeply influences their distribution within the sediment. Its knowledge is crucial to accurately estimate the volume of bound gas; accordingly it is relevant for both the assessment of seafloor stability and the prospecting of suitable hydrate-reservoirs for production. The configuration of our apparatus enables us to make valuable contributions in the understanding of the geologic factors controlling hydrate morphology. Here, attention has been focused on the formation of hydrates in three different geologic matrices composed of either sand or a mixture of clays and sand, and then the visual observation of the resulting morphology. Method 2 was chosen as formation procedure with a methane injection flow-rate of $57 \mathrm{mLn} / \mathrm{min}$. The sand has been sieved to have a particle size distribution between 180 and $360 \mu \mathrm{m}$. We voluntarily used the same amount of water, e.i. 100 $\mathrm{g}$, for all experiments in order to see the influence of the proportion of clays on the water really available for hydrate formation.

\section{Experiment in sand}

The first two experiments were carried out in silica sand. Fig.10 depicts a core which has been kept into the vessel for burning. As expected in coarse-grained sediment, the hydrates were disseminated $[10,33,56,57]$. A white and thin layer was formed at the interface between the core top and the porous stone (Fig. 10a and 10d) due to the discontinuity between both media acting like a change in lithology. Within the core, the hydrates looked like white small dots of about 2-3 mm-size unevenly distributed (Fig. 10b and 10e). Scattered hydrates were found close to the rim while they were much more concentrated in the center (Fig. 10c). In fact, the white color at the center indicates massive hydrate growth location which can be burst into flames (Fig. 10f). This distribution was found all along the core. It was suspected that the hydrates cement the sediment for it was not possible to drill through the core even by hammering a screwdriver from the top. Fig. 11 shows a second hydrate-bearing sand core formed in the frame of this study. It has been withdrawn from the high-pressure vessel to better appreciate the hydrate morphology. Again, a significant amount of hydrates was formed in between the porous stone and the core top (Fig. 11a and b). As for the previous pictures, the hydrates were disseminated within the core making them difficult to see from naked eyes. 
However, cm-size hydrates tend to accumulate within the channel created by the thermocouple and voids generated by the wrinkles of the polypropylene sheet.

Experiment in $5.82 \%$ mass of clay-matrix and $94.18 \%$ mass of sand By adding clays, the color of the matrix changed from yellowish color to gray. The hydrates were also disseminated, widespreadly dispersed and invisible from naked eyes (Fig. 12). In localized locations along the core, it was possible to take small pieces and clearly see the hydrate decomposition like the ones put on the porous stone (Fig. 12c).

Experiment in $19.80 \%$ mass of clay-matrix and $80.2 \%$ mass of sand

Here, the core was characterized by cracks close to which the sediment was wetter than elsewhere (Fig. 13). The hydrates exhibit a very different morphology. A massive hydrate lens was located at $2 \mathrm{~cm}$ depth from the core top. The sediment in the vicinity of this hydrate lens was dry, suggesting either water focusing prior to hydrate formation or water migration during the hydrate formation. Several dispersed patchy hydrates were also found along the core.

\section{Experiment in $40.3 \%$ mass of clay-matrix and $59.65 \%$ mass of sand}

Nearly the whole core was totally dry (Fig. 14). This is due to the intrinsic capacity of clays to adsorb water molecules. Even though kaolinite belongs to the group of clays having the smallest specific surfaces to tie water molecules by adsorption [58], one can clearly see from Fig. 14 a very dry and cracked core. Thus, the amount of water really available for hydrate formation is much less here than for the previously investigated cores. Our experiments clearly show that the amount of available water decreases by increasing the proportion of clays. However, in some very well localized points, moussy sediment was observed. It is indicative of either the occurrence of fine particles of hydrates or gas release by exsolution. Due to the dryness of the core and the hydrate dissociation-like noise associated with the moussy sediment, we believe that it is more likely the results of the dissociation of very fine particles of disseminated hydrates not visible from naked eyes.

\section{Conclusion}


In consideration of the growing concern for hydrate-bearing sediments and the limitation of kinetic models to fully describe their formation process, it is clear that laboratory-based experiments are necessary to improve our understanding on such systems. Therefore, a novel and compact apparatus has been designed and built for the monitoring of key physicochemical parameters such as pressure, temperature and gas flow rate during hydrate formation and destabilization processes. Several series of experiments have been carried out to illustrate its capabilities. They led to the following conclusions:

- Repeated experiments of hydrate formation in silica sand at a constant methane flow rate of $57 \mathrm{mLn} / \mathrm{min}$ showed a large variability in the incipient hydrateformation time. The latter decreases when increasing the flow rate and converges toward a limit value. The analysis of the pressure profiles as a function of time showed that hydrate formation in sand has not a unique kinetics pattern. Thus, hydrates grow at different points and in different ways within the solid matrix.

- The apparatus allows for the quantification of the hydrate-bound gas. For $100 \mathrm{~g}$ of injected water, the quantified volume of hydrate-bound methane can differ by nearly $2.5 \mathrm{~L}$ for experiments performed at different injection flow rates. We postulated that high injection flow-rate may favor the trapping of gas bubbles within the hydrate phase.

- To consider how the proportion of clays, mainly kaolinite, affects the hydrate morphology, three experiments were carried out at constant amount of injected water and constant methane flow rate. By increasing the amount of clays, the hydrate morphology changes from disseminated through massive to moussy.

Further experiments are required in order to achieve a good understanding of methanehydrate formation in sand and provide a better theoretical framework for the description of the system \{hydrates + matrix . More particularly, the importance of water mobility on the formation kinetics deserves deeper investigations. The evolution of the hydraulic conductivity and the pressure dissipation may also provide useful information regarding the hydrate growth mechanism during formation, and also hydrate reformation process during dissociation. Lastly, the determination of the critical clay content to shift from one 
hydrate morphology to another also merits more work. These would be the object of future studies.

\section{Acknowledgement}

This research was financially supported by the Institut Carnot Ifremer-EDROME. I would like to thank two anonymous reviewers for constructive comments and suggestions.

\section{References}

[1] Makogon Y, Holditch S, Makogon T. Natural gas-hydrates-A potential energy source for the 21st Century. Journal of Petroleum Science and Engineering. 2007;56:14-31.

[2] Max M. Natural gas hydrate: in oceanic and permafrost environments: Kluwer Academic Pub; 2003.

[3] Sloan ED. Fundamental principles and applications of natural gas hydrates. Nature. 2003;426:353-9.

[4] Sloan ED, Koh CA. Clathrate hydrates of natural gases: CRC Press; 2008.

[5] Kvenvolden KA. Methane hydrate - A major reservoir of carbon in the shallow geosphere. Chemical Geology. 1988;71:41-51.

[6] Paull C, Dillon W. Natural gas hydrates: occurrence, distribution, and detection: American Geophysical Union, Washington, DC; 2001.

[7] Milkov AV. Global estimates of hydrate-bound gas in marine sediments: how much is really out there? Earth-Science Reviews. 2004;66:183-97.

[8] Boswell R, Collett TS. Current perspectives on gas hydrate resources. Energy \& environmental science. 2011;4:1206-15.

[9] Collet T, Kuuskraa V. Hydrates contain vast store of world gas resources. Oil \& gas journal. 1998;96:90-5.

[10] Collett T, Johnson A, Knapp C, Boswell R. natural gas hydrates energy resource potential and associated geologic hazards. AAPG Memoir 89. 2010.

[11] Englezos P, Lee J. Gas hydrates: A cleaner source of energy and opportunity for innovative technologies. Korean Journal of Chemical Engineering. 2005;22:671-81.

[12] Max M, Johnson A, Dillon W. Economic geology of natural gas hydrate: Kluwer Academic Pub; 2006.

[13] Max M, Lowrie A. Oceanic methane hydrates: A frontier gas resource. Journal of Petroleum Geology. 1996;19:41-56.

[14] Bernardes LF, Carneiro J, de Abreu MP. CO2 hydrates as a climate change mitigation strategy: definition of stability zones in the Portuguese deep offshore. International Journal of Global Warming. 2013;5:135-51.

[15] Brewer PG, Peltzer ET, Friederich G, Aya I, Yamane K. Experiments on the ocean sequestration of fossil fuel $\mathrm{CO} 2: \mathrm{pH}$ measurements and hydrate formation. Marine Chemistry. 2000;72:83-93.

[16] Goel N. In situ methane hydrate dissociation with carbon dioxide sequestration: Current knowledge and issues. Journal of Petroleum Science and Engineering. 2006;51:169-84.

[17] Kvamme B, Graue A, Buanes T, Kumetsoua T, Ersland G. Storage of CO2 in natural gas hydrate reservoirs and the effect of hydrate as an extra sealing in cold aquifers. International Journal of Greenhouse Gas Control. 2007;1:236-46. 
[18] Lee K, Lee H, Lee J, Kang J. CO2 hydrate behavior in the deep ocean sediments; phase equilibrium, formation kinetics, and solubility. Geophysical Research Letters. 2002;29:2034.

[19] Qanbari F, Pooladi-Darvish M, Tabatabaie SH, Gerami S. CO2 disposal as hydrate in ocean sediments. Journal of Natural Gas Science and Engineering. 2012;8:139-49.

[20] Tohidi B, Yang J, Salehabadi M, Anderson R, Chapoy A. CO2 Hydrates Could Provide Secondary Safety Factor in Subsurface Sequestration of CO2. Environmental Science \& Technology. 2010;44:1509-14.

[21] Kvenvolden KA. Gas hydrate and humans. Annals of the New York Academy of Sciences. 2000;912:17-22.

[22] Marsset B, Thomas Y, Sultan N, Gaillot A, Stephan Y. A multi-disciplinary approach to marine shallow geohazard assessment. Near Surface Geophysics. 2012;10:279-88.

[23] Maslin M, Owen M, Betts R, Day S, Dunkley Jones T, Ridgwell A. Gas hydrates: past and future geohazard? Philosophical Transactions of the Royal Society a-Mathematical Physical and Engineering Sciences.368:2369-93.

[24] McConnell DR, Zhang Z, Boswell R. Review of progress in evaluating gas hydrate drilling hazards. Marine and Petroleum Geology. 2012;34:209-23.

[25] Sultan N, Cochonat P, Foucher J, Mienert J. Effect of gas hydrates melting on seafloor slope instability. Marine Geology. 2004;213:379-401.

[26] Bains S, Corfield RM, Norris RD. Mechanisms of climate warming at the end of the Paleocene. Science. 1999;285:724-7.

[27] Bice KL, Marotzke J. Could changing ocean circulation have destabilized methane hydrate at the Paleocene/Eocene boundary? Paleoceanography. 2002;17:8-1-8-12.

[28] Dickens GR, Castillo MM, Walker JC. A blast of gas in the latest Paleocene: Simulating first-order effects of massive dissociation of oceanic methane hydrate. Geology. 1997;25:25962.

[29] Henriet JP, Mienert J. Gas hydrates: relevance to world margin stability and climate change: Geological Society Pub House; 1998.

[30] Kennett JP, Cannariato KG, Hendy IL, Behl RJ. Methane hydrates in Quaternary climate change: The clathrate gun hypothesis: American Geophysical Union; 2003.

[31] Krey V, Canadell JG, Nakicenovic N, Abe Y, Andruleit H, Archer D, et al. Gas hydrates: entrance to a methane age or climate threat? Environmental Research Letters. 2009;4.

[32] Kwon T-H, Cho G-C. Submarine Slope Failure Primed and Triggered by Bottom Water Warming in Oceanic Hydrate-Bearing Deposits. Energies. 2012;5:2849-73.

[33] Waite WF, Santamarina JC, Cortes DD, Dugan B, Espinoza DN, Germaine J, et al. Physical properties of hydrate-bearing sediments. Reviews of Geophysics. 2009;47.

[34] Sultan N, Bohrmann G, Ruffine L, Pape T, Riboulot V, Colliat JL, et al. Pockmark formation and evolution in deep water Nigeria: Rapid hydrate growth versus slow hydrate dissolution. Journal of Geophysical Research-Solid Earth. 2014;119:2679-94.

[35] Torres M, Wallmann K, Trehu A, Bohrmann G, Borowski W, Tomaru H. Gas hydrate growth, methane transport, and chloride enrichment at the southern summit of Hydrate Ridge, Cascadia margin off Oregon. Earth and Planetary Science Letters. 2004;226:225-41.

[36] Changyu S, Wenzhi L, Xin Y, Fengguang L, Qing Y, Liang M, et al. Progress in Research of Gas Hydrate. Chinese Journal of Chemical Engineering. 2011;19:151-62.

[37] Sun X, Mohanty KK. Kinetic simulation of methane hydrate formation and dissociation in porous media. Chemical Engineering Science. 2006;61:3476-95.

[38] Brewer PG, Orr FM, Friederich G, Kvenvolden KA, Orange DL, McFarlane J, et al. Deep-ocean field test of methane hydrate formation from a remotely operated vehicle. Geology. 1997;25:407-10.

[39] Jung J-W, Santamarina JC. Hydrate formation and growth in pores. Journal of Crystal Growth. 2012;345:61-8. 
[40] Kono HO, Narasimhan S, Song F, Smith DH. Synthesis of methane gas hydrate in porous sediments and its dissociation by depressurizing. Powder Technology. 2002;122:23946.

[41] Linga P, Haligva C, Nam SC, Ripmeester JA, Englezos P. Gas Hydrate Formation in a Variable Volume Bed of Silica Sand Particles. Energy \& Fuels. 2009;23:5496-507.

[42] Madden M, Ulrich S, Szymcek P, McCallum S, Phelps T. Experimental formation of massive hydrate deposits from accumulation of $\mathrm{CH} 4$ gas bubbles within synthetic and natural sediments. Marine and Petroleum Geology. 2009;26:369-78.

[43] Stevens J, Baldwin B, Graue A, Ersland G, Husebo J, Howard J. Measurements of hydrate formation in sandstone. Petrophysics. 2008;49:67.

[44] Su K-H, Sun C-Y, Dandekar A, Liu B, Sun W-Z, Cao M-C, et al. Experimental investigation of hydrate accumulation distribution in gas seeping system using a large scale three-dimensional simulation device. Chemical Engineering Science. 2012;82:246-59.

[45] Tohidi B, Anderson R, Clennell MB, Burgass RW, Biderkab AB. Visual observation of gas-hydrate formation and dissociation in synthetic porous media by means of glass micromodels. Geology. 2001;29:867-70.

[46] Zang X, Liang D, Wu N. Gas hydrate formation in fine sand. Science China-Earth Sciences. 2013;56:549-56.

[47] Schicks JM, Spangenberg E, Giese R, Steinhauer B, Klump J, Luzi M. New Approaches for the Production of Hydrocarbons from Hydrate Bearing Sediments. Energies. 2011;4:15172.

[48] Spangenberg E, Kulenkampff J, Naumann R, Erzinger J. Pore space hydrate formation in a glass bead sample from methane dissolved in water. Geophysical Research Letters. 2005;32. [49] Priest JA, Rees EV, Clayton CR. Influence of gas hydrate morphology on the seismic velocities of sands. Journal of Geophysical Research: Solid Earth (1978-2012). 2009;114.

[50] Su K-H, Sun C-Y, Dandekar A, Liu B, Sun W-Z, Cao M-C, et al. Experimental investigation of hydrate accumulation distribution in gas seeping system using a large scale three-dimensional simulation device. Chemical Engineering Science. 2012.

[51] Kim JH, Park MH, Chun JH, Lee JY. Molecular and isotopic signatures in sediments and gas hydrate of the central/southwestern Ulleung Basin: high alkalinity escape fuelled by biogenically sourced methane. Geo-Marine Letters. 2011;31:37-49.

[52] Sultan N. Guineco-MeBo Cruise report. Personal communication. 2012.

[53] Bagherzadeh SA, Moudrakovski IL, Ripmeester JA, Englezos P. Magnetic resonance imaging of gas hydrate formation in a bed of silica sand particles. Energy \& Fuels. 2011;25:3083-92.

[54] Babu P, Yee D, Linga P, Palmer A, Khoo BC, Tan TS, et al. Morphology of Methane Hydrate Formation in Porous Media. Energy \& Fuels. 2013;27:3364-72.

[55] Suess E, Torres M, Bohrmann G, Collier R, Rickert D, Goldfinger C, et al. Sea floor methane hydrates at Hydrate Ridge, Cascadia margin. Natural gas hydrates: occurrence, distribution, and detection. 2001:87-98.

[56] Dai S, Santamarina JC, Waite WF, Kneafsey TJ. Hydrate morphology: Physical properties of sands with patchy hydrate saturation. Journal of Geophysical Research: Solid Earth (1978-2012). 2012;117.

[57] Holland M, Schultheiss P, Roberts J, Druce M. Observed gas hydrate morphologies in marine sediments. Paper 5691 presented at the 6th International Conference on Gas Hydrates (ICGH 2008), Vancouver, B C, Canada, 6-10 July. 2008.

[58] Uchida T, Takeya S, Chuvilin EM, Ohmura R, Nagao J, Yakushev VS, et al. Decomposition of methane hydrates in sand, sandstone, clays, and glass beads. Journal of Geophysical Research: Solid Earth (1978-2012). 2004;109. 


\section{Table 1.}

Incipient hydrate-formation time for experiments of methane-hydrate formation performed at methane flow-rate of $57 \mathrm{mLn} / \mathrm{min}$.

\begin{tabular}{ccc}
\hline $\begin{array}{c}\text { Experiment } \\
\text { Number }\end{array}$ & $\begin{array}{c}\text { Incipient hydrate } \\
\text { formation time/min. }\end{array}$ & $\begin{array}{c}\text { Incipient hydrate } \\
\text { formation pressure/bar }\end{array}$ \\
\hline Exp_1 & 72 & 49.62 \\
Exp_2 & 68 & 57.77 \\
Exp_3 & 52 & 48.99 \\
Exp_4 & 80 & 59.15 \\
Exp_5 & 122 & 70.49 \\
Exp_6 & 138 & 75.55 \\
\hline
\end{tabular}


Table 2.

Values of monitored parameters for methane-hydrate formation and dissociation within silica sand with particle size in between $180-500 \mu \mathrm{m}$ at different methane flow-rate.

\begin{tabular}{ccccc}
\hline Experiment & $\begin{array}{c}\text { Methane flow } \\
\text { rate mLn/min }\end{array}$ & $\begin{array}{c}\text { Incipient hydrate } \\
\text { formation time/ } \\
\text { min. }\end{array}$ & $\begin{array}{c}\text { Incipient hydrate } \\
\text { formation pressure/bar }\end{array}$ & $\begin{array}{c}\text { Volume of hydrate- } \\
\text { bound methane/Ln }\end{array}$ \\
\hline VFlow_Exp_1 & 29 & 110 & 44.66 & 17.42 \\
VFlow_Exp_2 & 57 & 72 & 49.62 & 17.31 \\
VFlow_Exp_3 & 85 & 34 & 45.13 & 18.37 \\
VFlow_Exp_4 & 114 & 30 & 44.44 & 17.83 \\
VFlow_Exp_5 & 171 & 38 & 54.18 & 19.78 \\
\hline
\end{tabular}




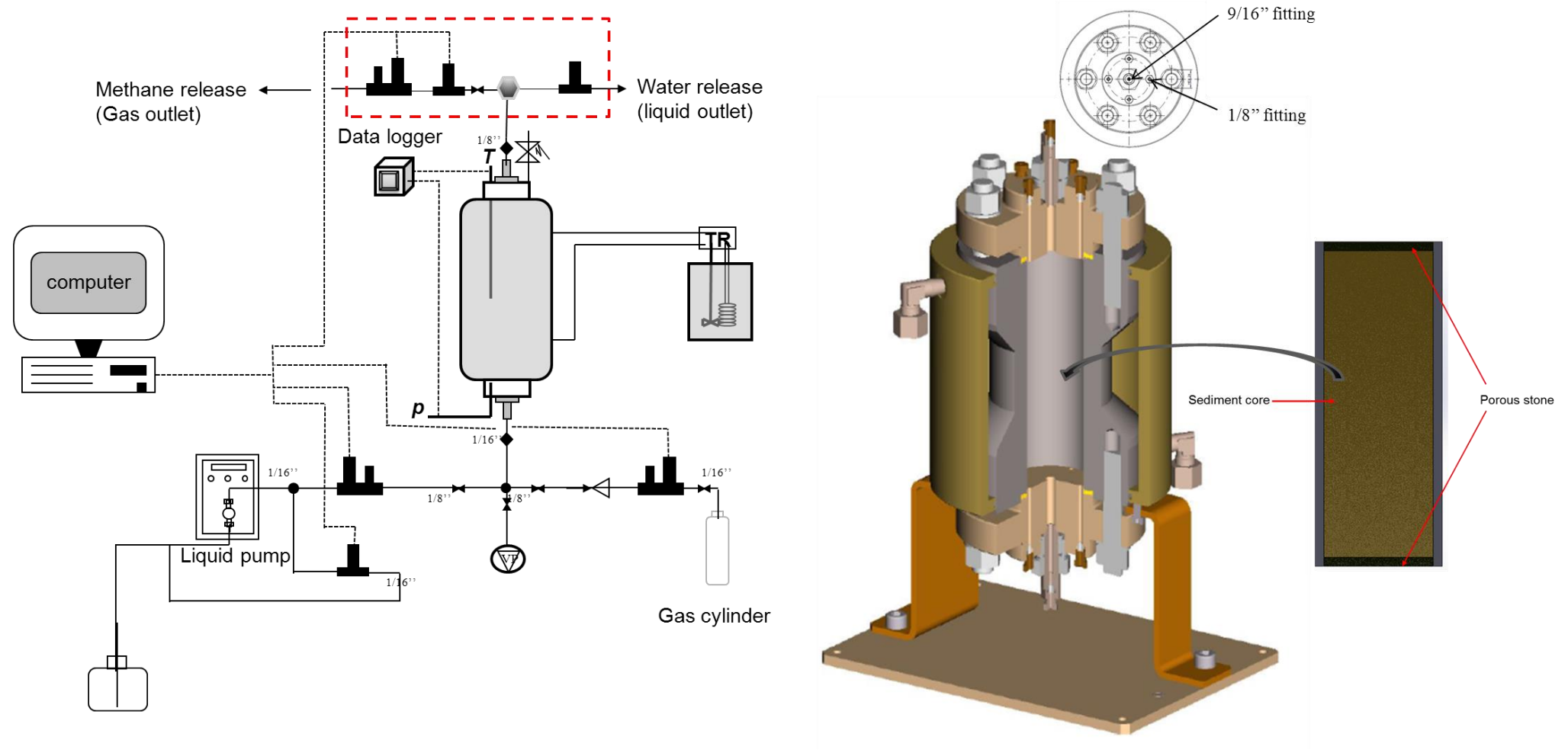

Figure 1. Schematic diagram of the apparatus. Elements: $(\mathrm{T})$ thermocouple, $(\mathrm{P})$ pressure

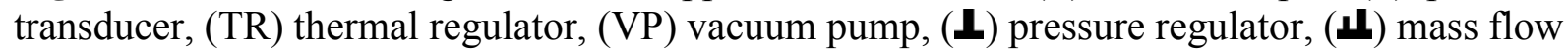
controller, ( $)$ high-pressure filter for gas-water separation, ( $\bullet$ high-pressure 2- $\mu \mathrm{m}$ filter, (\$) relief valve. 

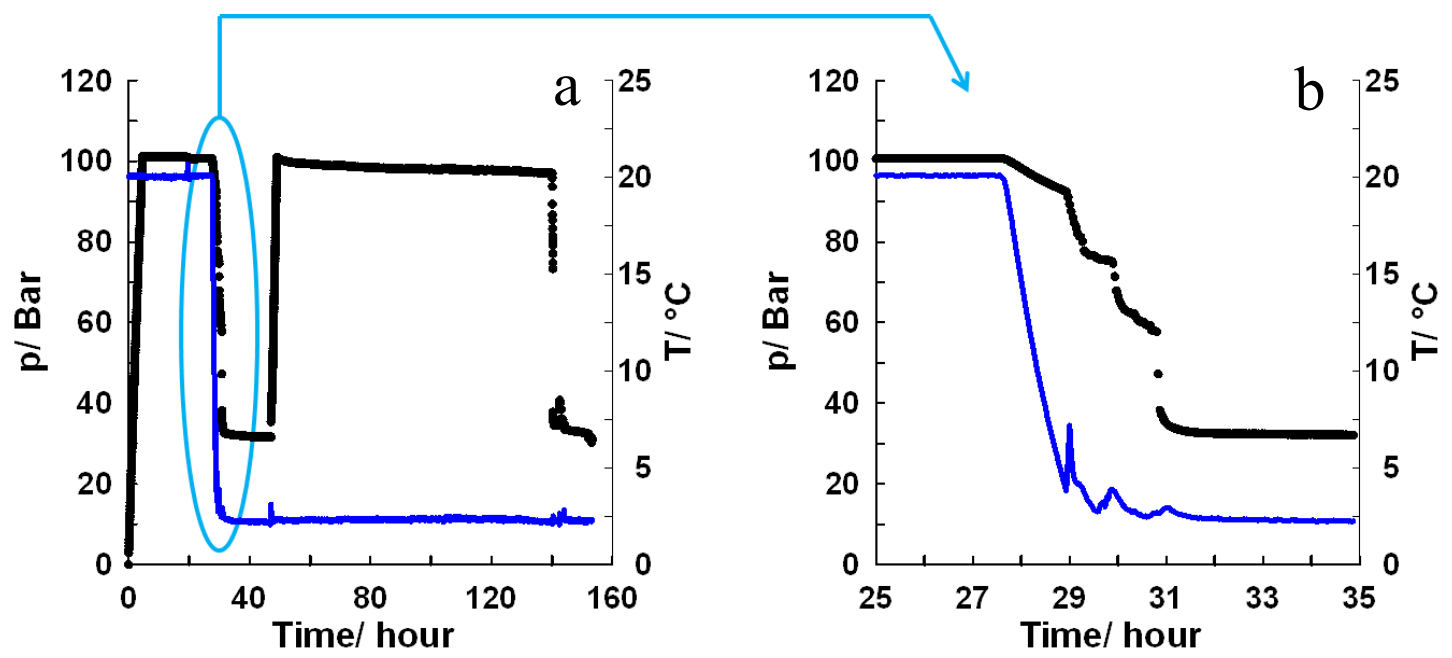

Figure 2. a) Example of temperature and pressure profiles as a function of time obtained by applying method 1 for hydrate formation. b) Magnified view of the hydrate-formation time interval; (_) pressure and (_) temperature. A second methane injection was possible at $\sim 50 \mathrm{~h}$ after a heating of the gas inlet. 

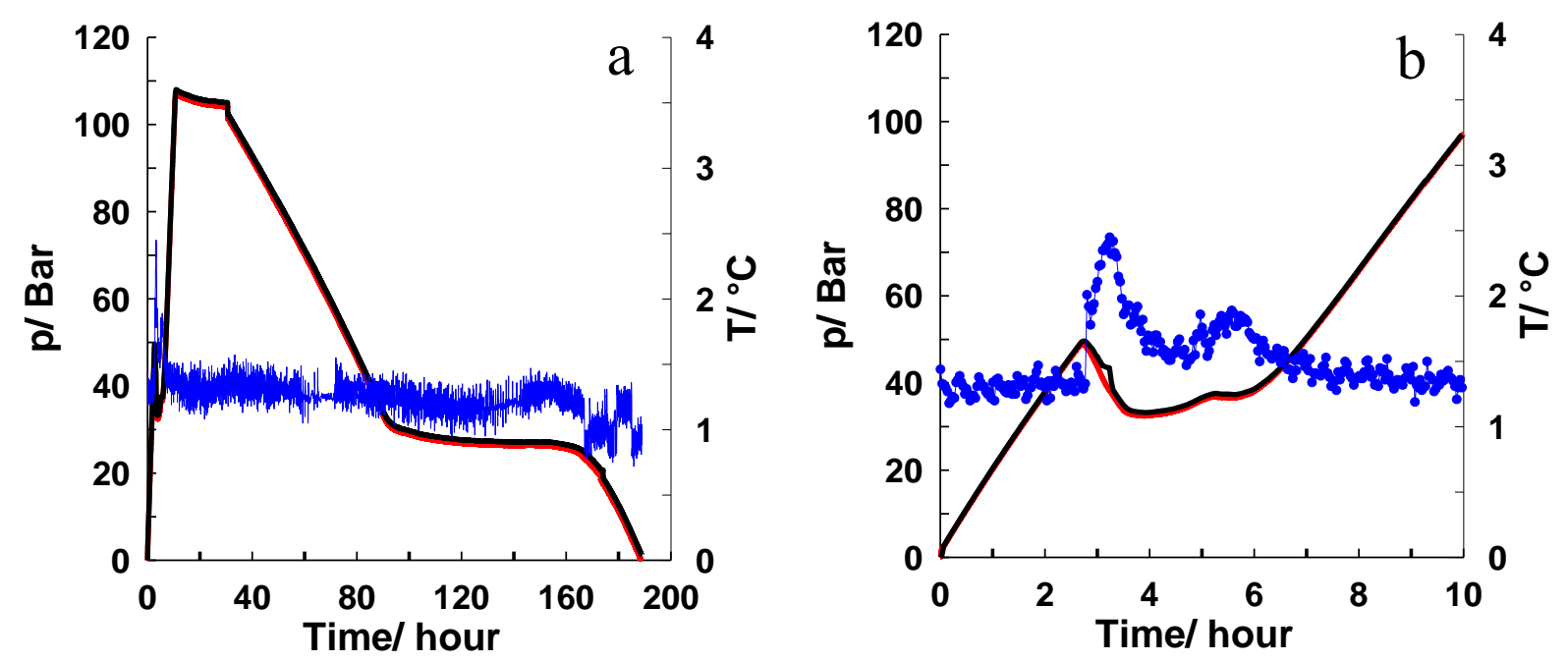

Figure 3. a) Example of temperature and pressure profiles as a function of time obtained by applying method 2 of hydrate formation. b) Magnified view of the hydrate-formation time interval; (_) downstream pressure, (_) upstream pressure and (_) temperature. 


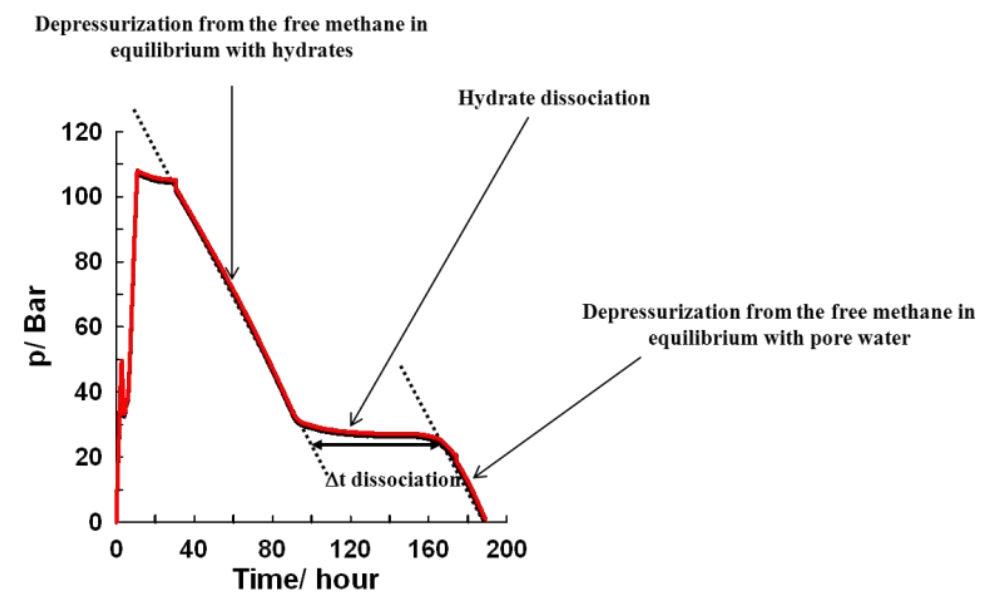

Figure 4. Method of quantification of the hydrate-bound gas: The plateau corresponds to the release of methane from the hydrates at constant flow rate and small pressure variation. 


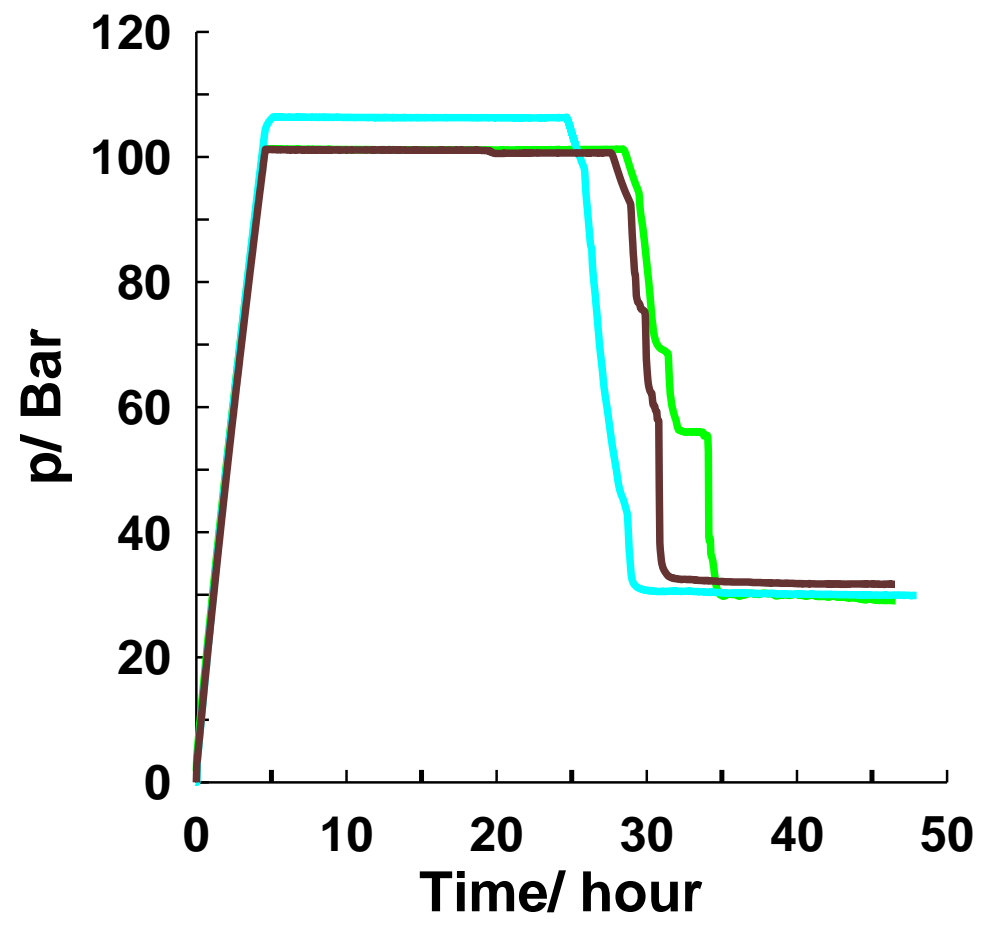

Figure 5. Pressure profiles as a function of time during methane-hydrate formation using method 1; (一) Exp_A, (_) Exp_B and (_) Exp_C. 

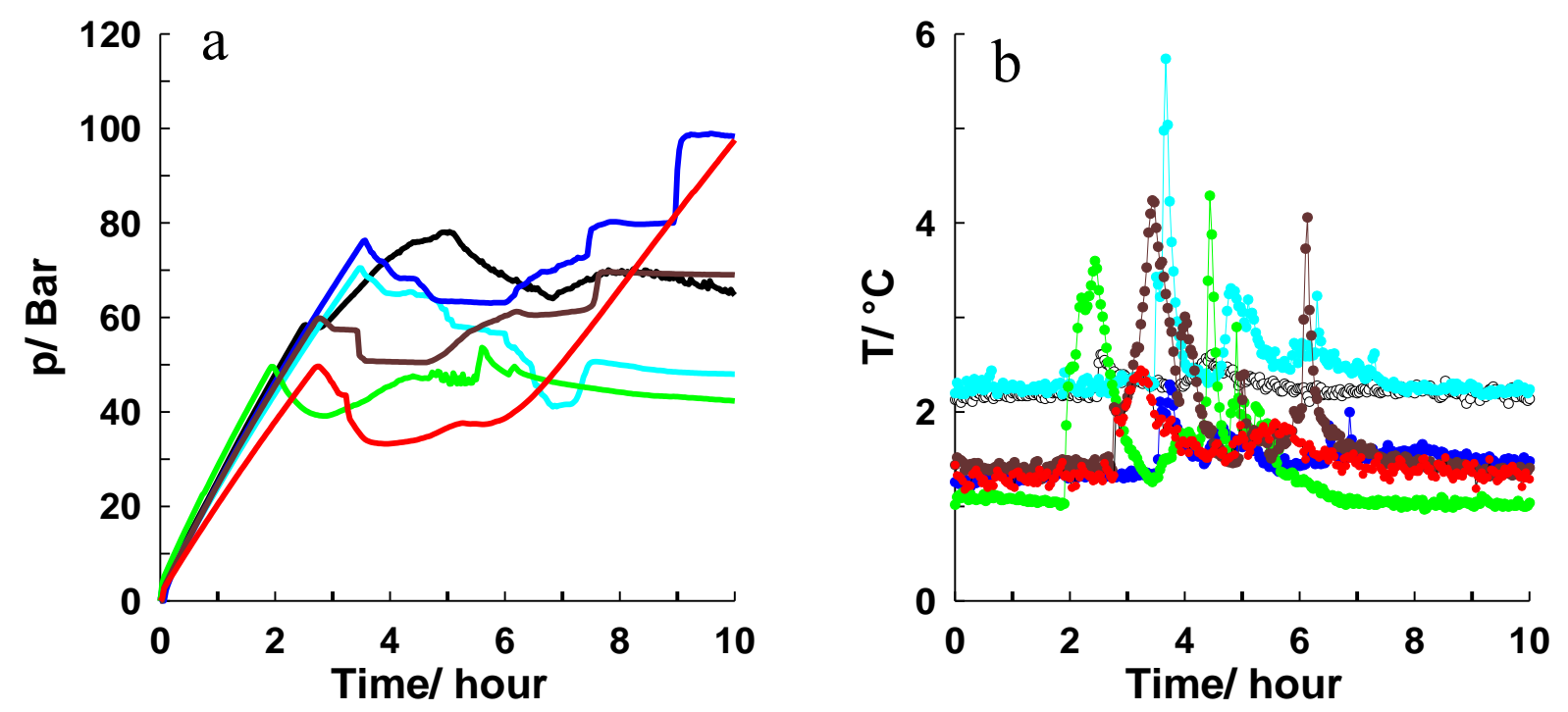

Figure 6. a) Pressure- time and b) temperature- time profiles for methane-hydrate formation and dissociation using method 2; (_) Exp_1, (_) Exp_2, (_) Exp_3, (_) Exp_4, (_) Exp_5 and (_) Exp_6. 

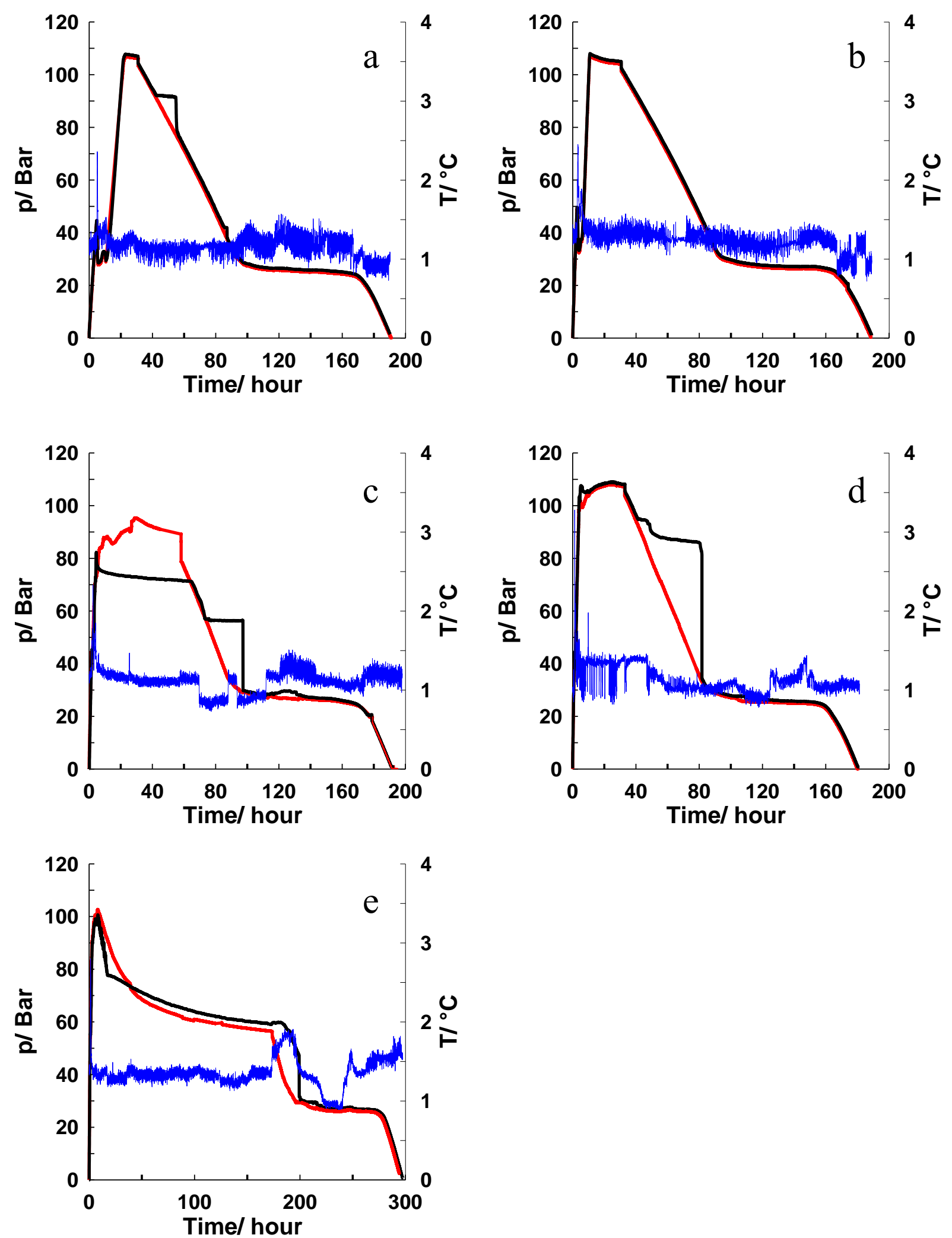

Figure 7. Pressure- temperature- time profiles for methane-hydrate formation and dissociation at different methane flow rates; a) $29 \mathrm{mLn} / \mathrm{min}$, b) $57 \mathrm{mLn} / \mathrm{min}$, c) $85 \mathrm{mLn} / \mathrm{min}$, d) 114 $\mathrm{mLn} / \mathrm{min}$, e) $171 \mathrm{mLn} / \mathrm{min}$; (-) downstream pressure, (-) upstream pressure and (-) temperature. 

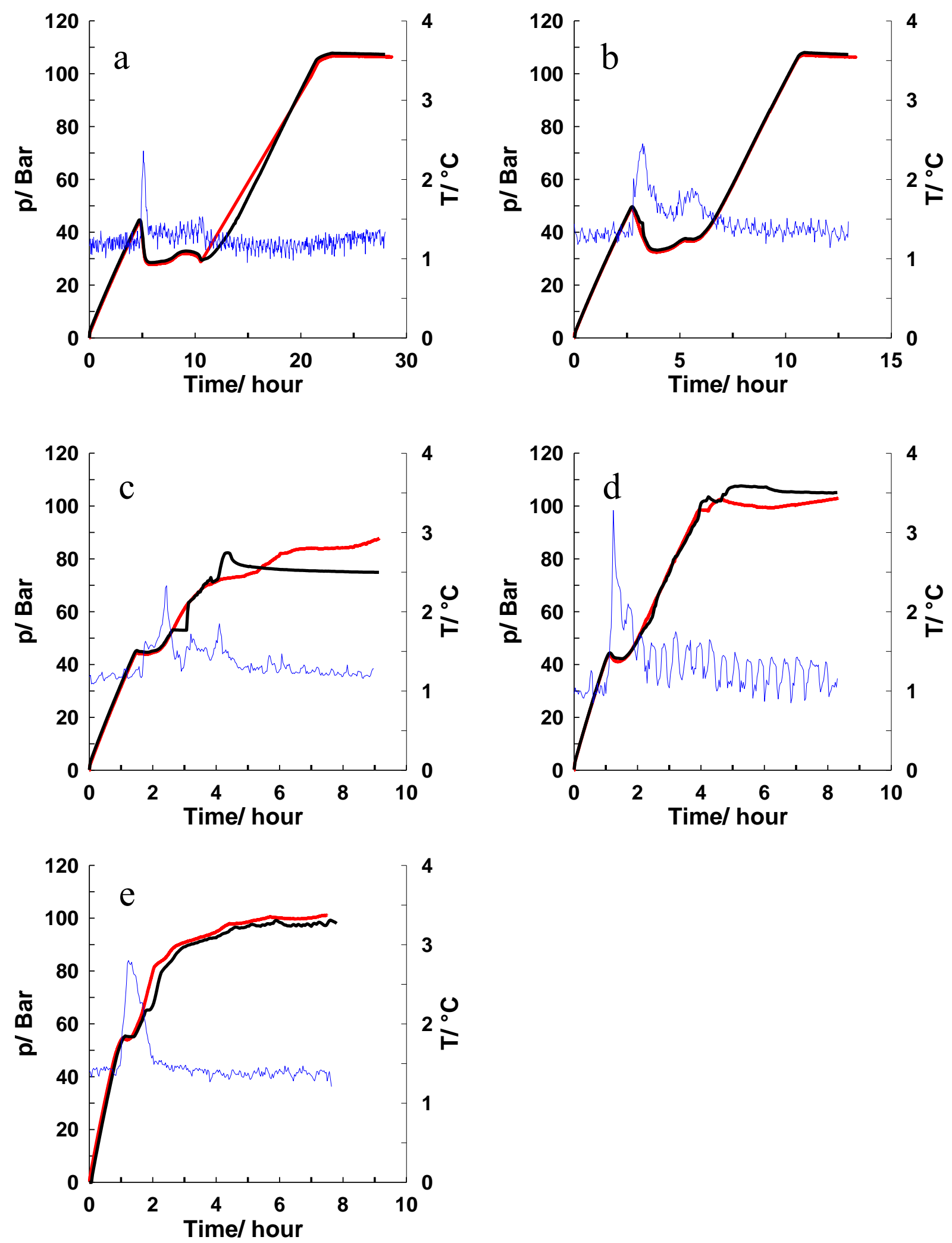

Figure 8. Magnified view of the formation time interval; a) $29 \mathrm{mLn} / \mathrm{min}$, b) $57 \mathrm{mLn} / \mathrm{min}$, c) $85 \mathrm{mLn} / \mathrm{min}$, d) $114 \mathrm{mLn} / \mathrm{min}$, e) $171 \mathrm{mLn} / \mathrm{min}$; (_) downstream pressure, (_) upstream pressure and (-) temperature. 


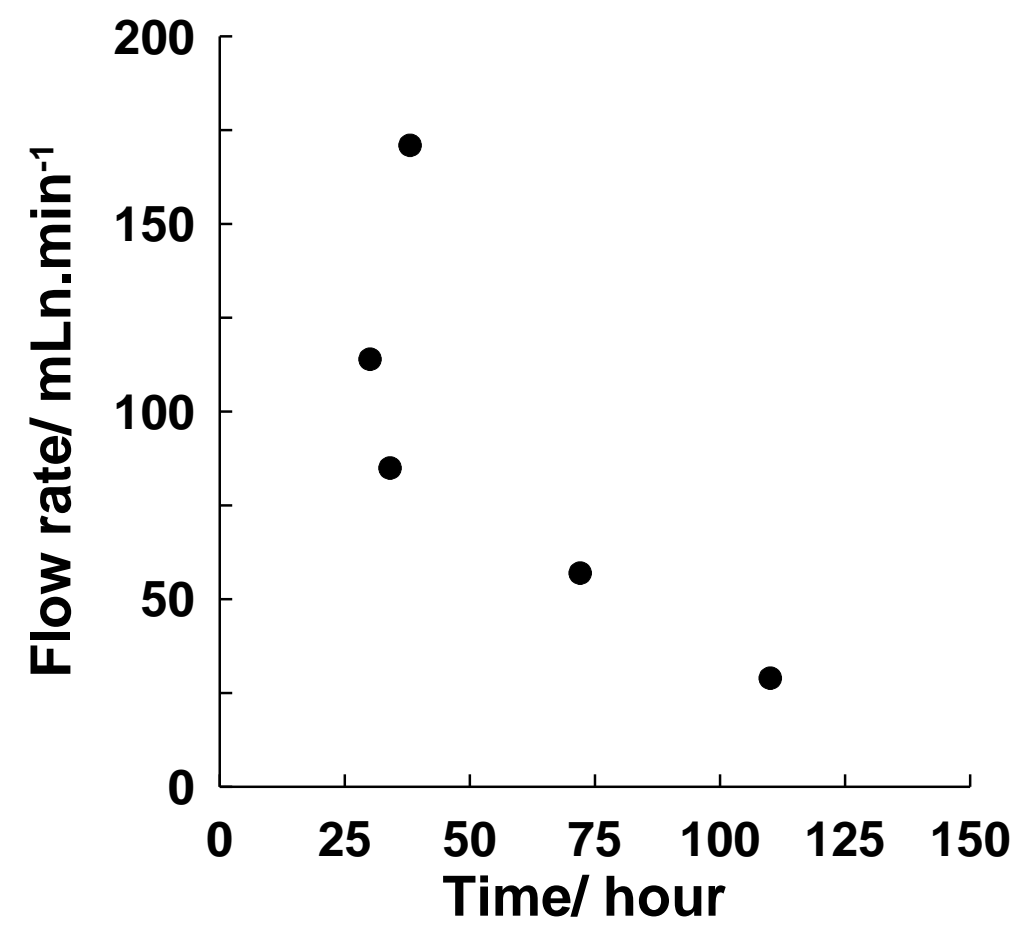

Figure 9. Incipient hydrate-formation time as a function of methane flow rate. 

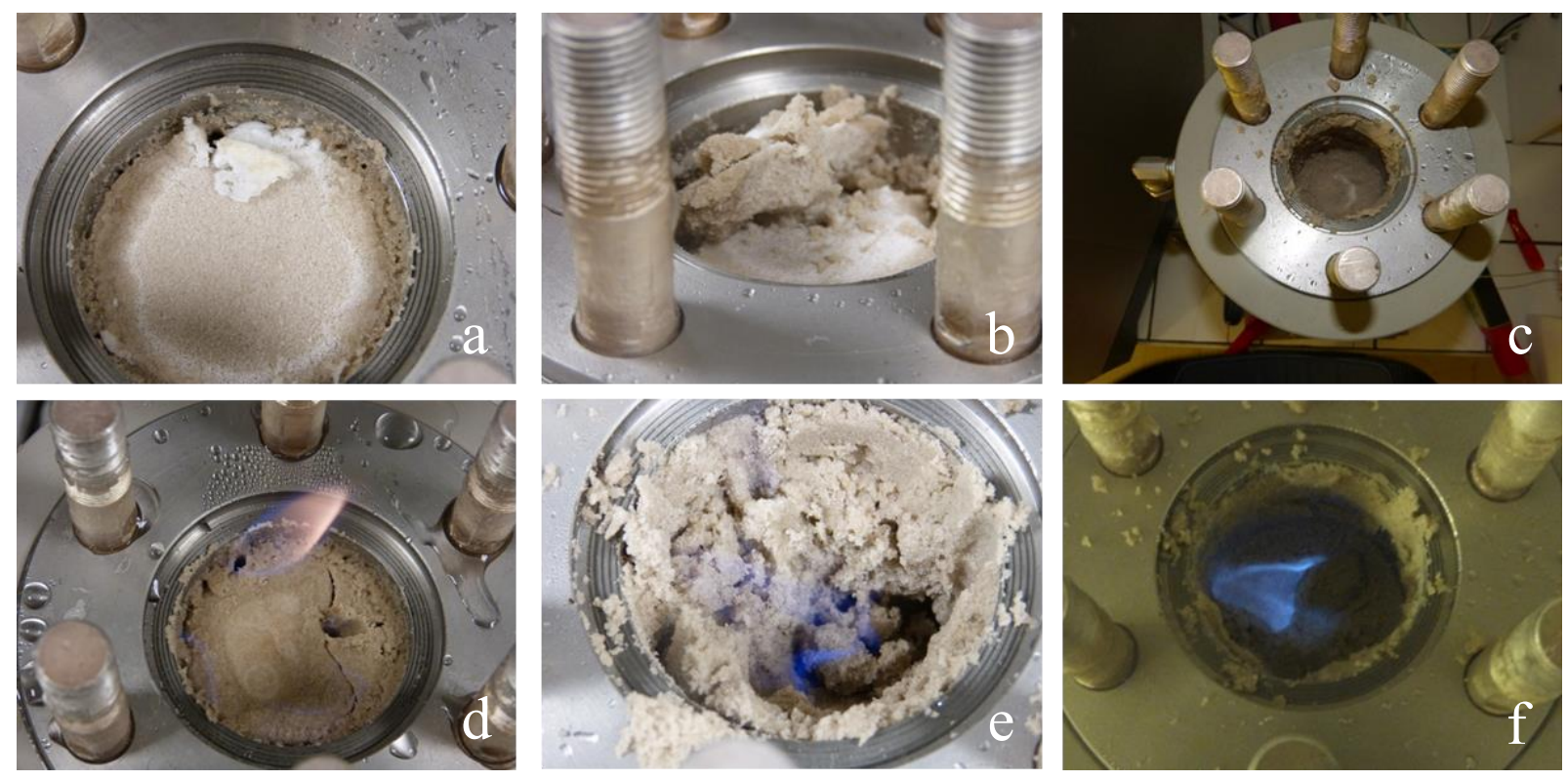

Figure 10. Methane-hydrate formation in silica sand: core burst into flame from the vessel. 

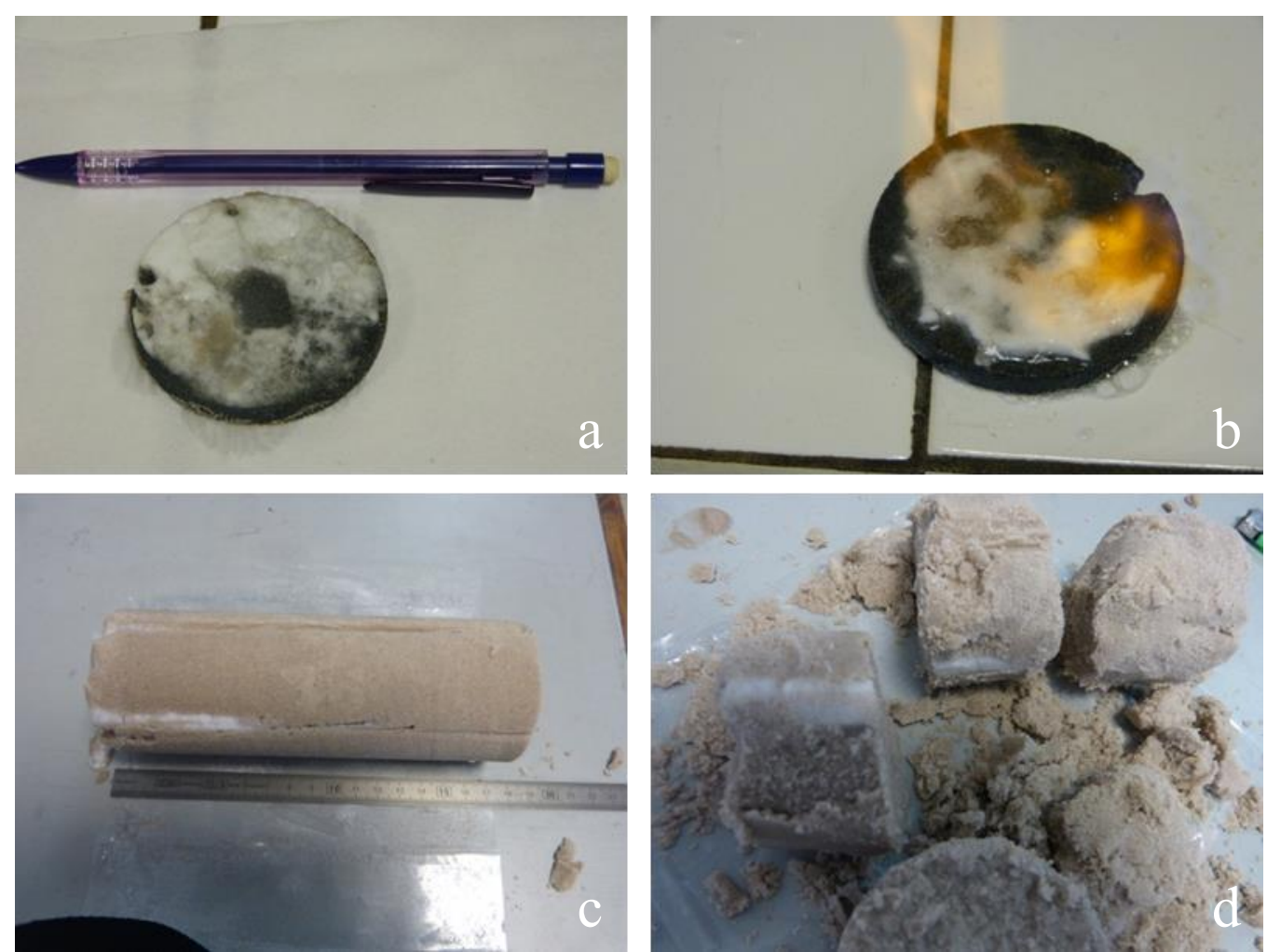

Figure 11. Methane-hydrate formation in silica sand: core retrieved from the vessel. 


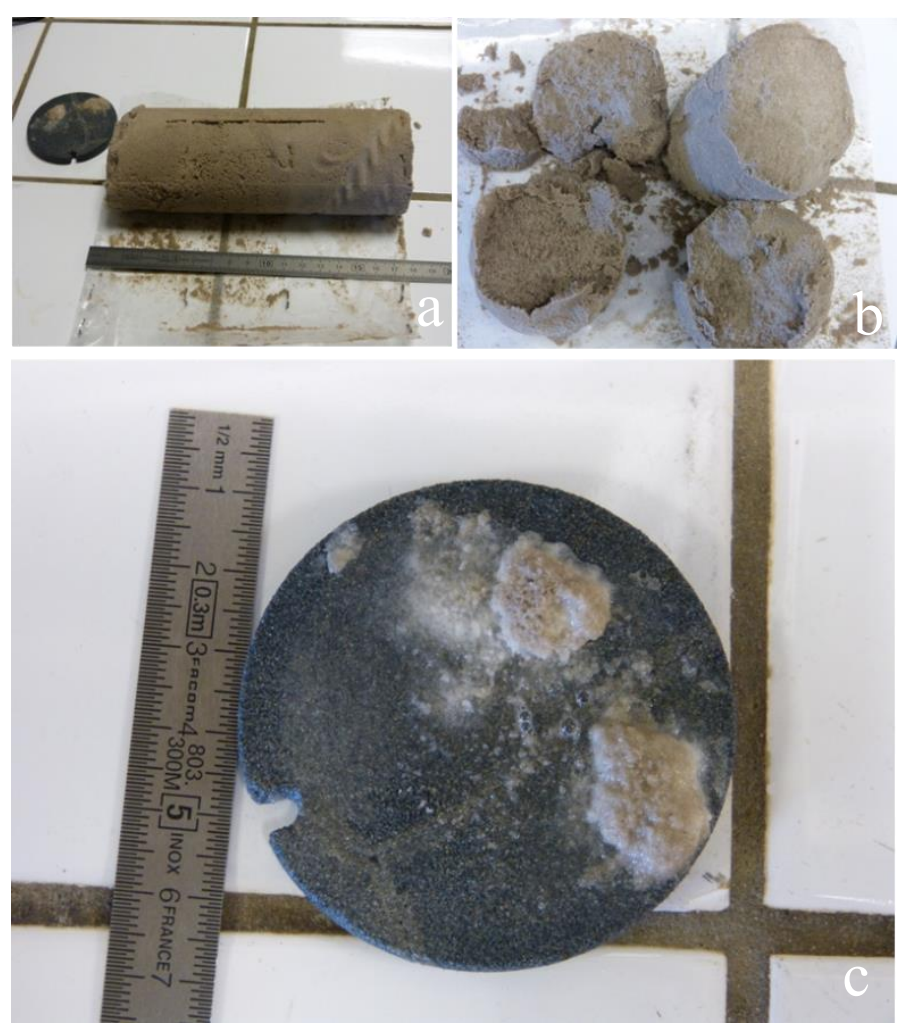

Figure 12. Methane-hydrate formation in a $5.82 \%$ mass of clay-matrix and $94.18 \%$ mass of sand. 

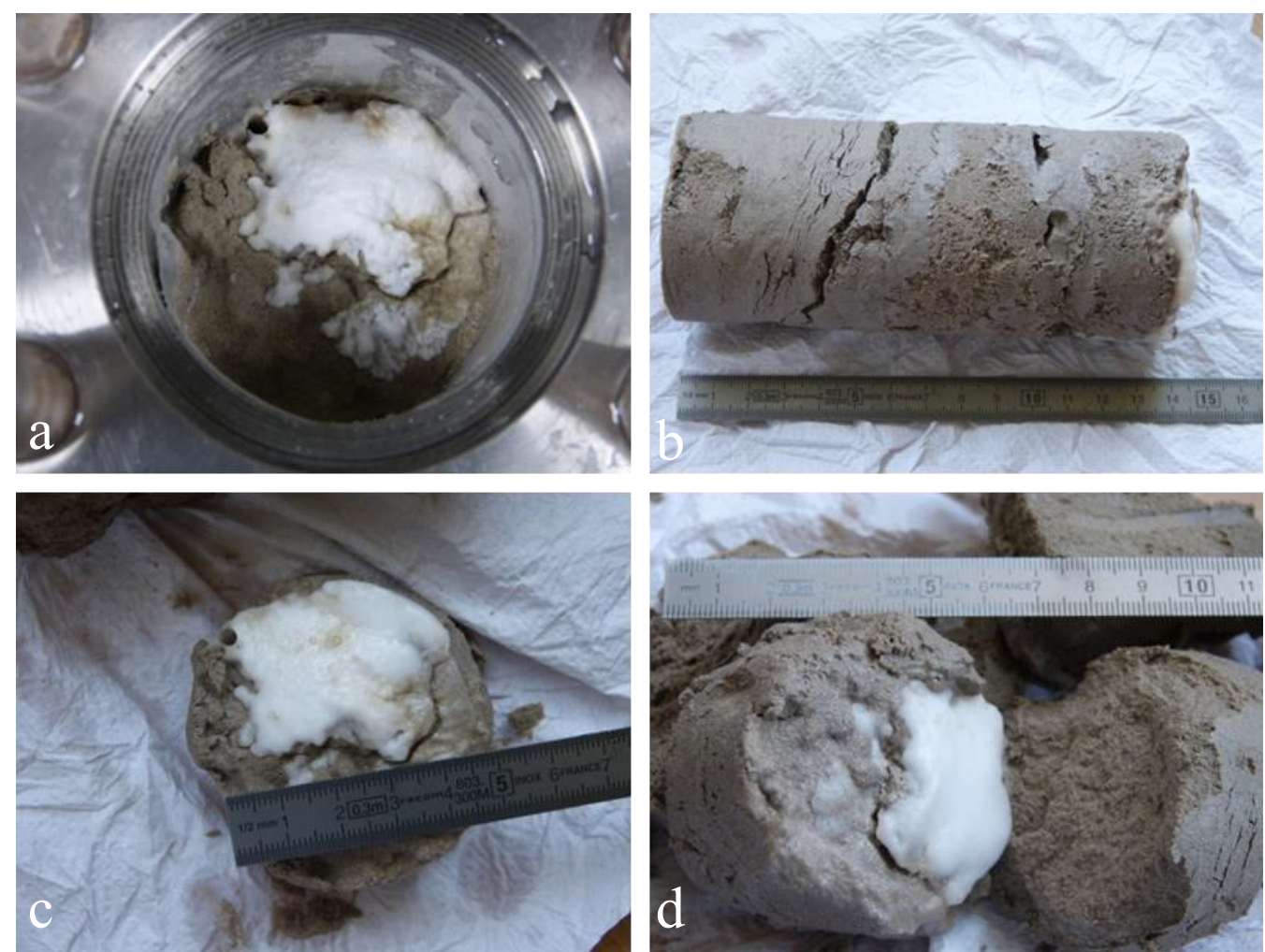

Figure 13. Methane-hydrate formation in a $19.80 \%$ mass of clay-matrix and $80.20 \%$ mass of sand. 

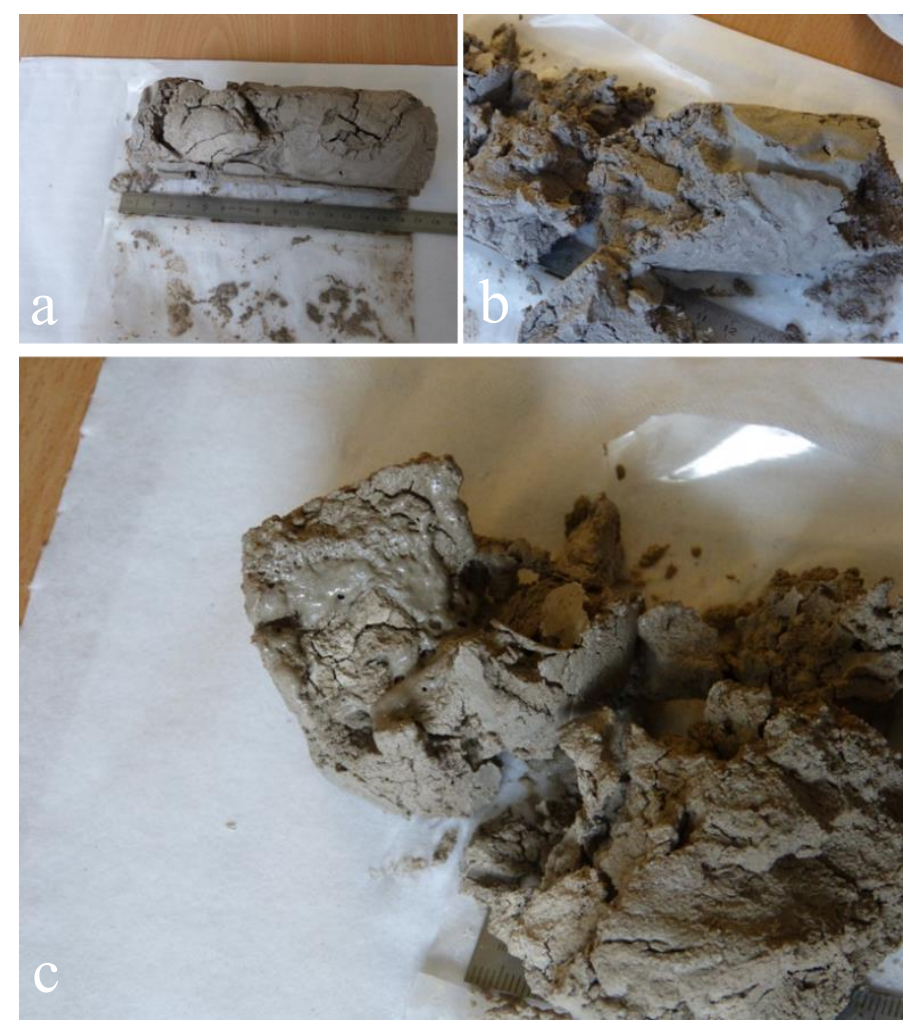

Figure 14. Methane-hydrate formation in a $40.35 \%$ mass of clay-matrix and $59.65 \%$ mass of sand. 